(C) 2018 IEEE. Personal use of this material is permitted. Permission from IEEE must be obtained for all other uses, in any current or future media, including reprinting/republishing this material for advertising or promotional purposes, creating new collective works, for resale or redistribution to servers or lists, or reuse of any copyrighted component of this work in other works. 


\title{
Hardware-In-The-Loop Simulation For The Design And Testing Of Motor In Advanced Powertrain Applications
}

\author{
Mohamed Awadallah ${ }^{1}$, Peter Tawadros ${ }^{2}$, Dr. Paul Walker ${ }^{3}$, Prof. Nong Zhang ${ }^{4}$ \\ School of Mechanical and Mechatronic Systems, University of Technology Sydney - UTS \\ Mohamed.M.Awadallah@student.uts.edu.au ${ }^{1}$,eng.m.zakaria@gmail.com¹, Peter.Tawadros@uts.edu.au², \\ Paul.Walker@uts.edu.au ${ }^{3}$,Nong.Zhang@uts.edu.au ${ }^{4}$.
}

\begin{abstract}
In this work, a validation procedure is presented, for an electric propulsion system used in a mild hybrid electric vehicle powertrain. The vehicle is configured based upon a brushless DC (permanent magnet synchronous) motor installed as electric propulsion system in a mild hybrid electric vehicle. Hardware-in-the-loop (HIL) techniques are used to enable rapid prototyping, as well as validate the specified characteristics of the motor unit, which was purchased as an off-the-shelf item. The validation results of the work in summary indicate that whilst the motor unit does not meet quoted specifications, it nevertheless functions acceptably for the purpose of the hybrid electric vehicle application.
\end{abstract}

Keywords-BLDC; Electric Propulsion; Hardware - in - the loop (HIL); Hybrid Electric Vehicles; Powertrain; Rapid prototyping; $\mathrm{P3} \mathrm{MHEV}$;

\section{INTRODUCTION}

Mild hybrid vehicles (MHEV) can perhaps best be thought of as a "compromise", avoiding the costs of a full-hybrid as well as the fuel consumption and emissions of a traditional internal combustion engine vehicle. It is this compromise that leads us to observe that the mild hybrid vehicle may be very well-suited to developing regions, where price-sensitivity is often as high as the need for better fleet emissions performance. One of the major goals of the work described is to investigate the needs of markets in developing regions, and develop a vehicle that fulfils them, inasmuch as it has a low enough manufacturing cost to be competitive in such markets, whilst delivering a measurable and significant improvement on emissions performance. A major focus is on the simplification of the model to allow rapid prototyping and validation of the Electric Propulsion System (EPS), which is a collative term for the all the components that comprise the electric side of the hybrid powertrain; namely, controller, power converter, energy storage device, and motor. [1].

The design of the EPS is referenced to specific requirements in terms of system constraints, energy storage practicalities, and vehicle benchmarks, which may include dynamic performance targets, as well as noise, vibration and harshness (NVH), drivability or other, sometimes qualitative characteristics. Extensive literature exists in this regard. One of the difficulties of EPS design for an HEV lies in the fact that the motor operating point is generally not defined due to the variety of the driving environment, making it difficult to design an effective EPS [2-4].

There are many advantages of electric motors as compared to internal combustion engines. Principally among these is their high energy conversion efficiency, which ranges between 70 to over 95\%. Electric motors are torque and power dense, providing maximum torque at zero speed. Many motor designs are also reversible, allowing for the conversion of kinetic energy to electricity through regenerative braking. Their quietness and smooth running also have significant advantages in terms of driver comfort and NVH. However, the choice of the motor in an HEV application requires careful consideration. There are a number of methodologies developed by the automotive industry to make appropriate electric propulsion system (EPS) design choices. Factors that are considered include efficiency, reliability, cost, and usage profile. The system-level factors feed into component-level selection generally by iteration. Prior literature in this field has used torque density, energy efficiency, cooling, cost, inverter size, speed and acceleration, drive profile, safety and reliability as inputs to the design process. In addition, vehicle layout, powertrain layout, and mechanical efficiency also must be taken into account when making design selections [5]. Motor characteristic evaluation and motor selection based on vehicle performance requirements. Furthermore, some of the major technical outcomes, particularly control and behaviour, are verified using HIL simulation of an exemplary powertrain system.

\section{A. Motor type selection}

Efficiency profile and speed range characteristics are two primary considerations when selecting traction motors. EV drivetrains may be based on a number of motor types, including permanent magnet motors (PMM), switched reluctance motors (SRM), induction motors (IM), and brushed DC motors (DC). Each type of motor has its own benefits and drawbacks. For instance, a DC motor relies on brushes and commutator rings, reducing the motor's effective speed and efficiency, as well as creating high electrical noise and sparking. This type of motor also requires frequent maintenance. In contrast, an IM has the advantage of increased speed range and field-oriented control. IM's are frequently used in EV-HEV applications as it is a technology that is both well understood and has established manufacturing 
infrastructure whilst introducing new drawbacks such as nonlinearity of the IM model, and high dependency on motor parameters to achieve positive control. Looking further at the SRM type, it offers the highest power density and allows torque is boosting through phase advancing. Considering this, it would be an appropriate consideration for SRM to qualify for use for EV, series HEV and low hybridised parallel HEV applications. However, it is noisy, and control is machine dependent and non-linear. Table I shows an evaluation of most commercially available electric motors for vehicle propulsion systems $[6,7]$. The evaluation grades the major characteristics of each motor from 1 to 5, representing the worst to best performance. Brushless PM motors are found to be highly capable when used for HEV propulsion applications, comparing rather favourably with IMs. It is no accident that they represent the majority of electric propulsion devices in consumer vehicles to date. The brushless PM motor offers high power density, increased efficiency, and effective heat dissipation. Its drawbacks include limited field-weakening, resulting in a smaller constant-power region. This is a consequence of the permanent magnet field, which also has the effect of the reduced speed range [8,9].

In the initial stage of the project, an extensive design study suggested that the best motor option for a low-cost MHEV is that of a The Permanent Magnet Synchronous Motor (PMSM), with a rated continuous mechanical power output of $10 \mathrm{~kW}$. PMSM drive is widely used for EV and HEV applications. The major advantages of PMSM motor include high efficiency, low maintenance, good longevity and reliability, low noise emissions, and low cogging torque. Importantly, the control of a PMSM motor is also considerably cheaper than other suitable candidates (e.g. IM, and SRM). PMSM has proven itself an adequately proficient motor for a $50 \%$ hybridized car. This is based on many preliminary studies conducted by the author on wide speed rangeability and energy efficiency. It was shown that it demonstrated superior efficiency in a constant torque regime. The disadvantages to its use include cost, safety and cooling. One cost that proved to be expensive were the large magnets for high-power PMSM. They also have a sensitivity to high temperature. In addition to this, there remain unfortunate consequences caused by the permanent field in the instance of short circuit faults. If measures are not implemented to cool the magnet, a decline in motor efficiency is observed. More manufacturers take the PMSM as the primary option for their EVs and HEVs, such as Chevrolet Spark EV, BMW i3, VW eGolf, Mercedes B250e, Nissan Leaf, Toyota Prius, Honda Insight and so on [10].

Generally, PMSM can be classified into two types by the control methods, i.e. brushless DC (BLDC), or brushless AC (BLAC).

TABLE I. QUALITATIVE COMPARISON OF COMMERCIAL ELECTRIC MOTORS.

\begin{tabular}{|l|l|l|l|l|}
\hline & PMSM & IM & $\begin{array}{l}\text { Brushed } \\
\text { DC Motor }\end{array}$ & SRM \\
\hline Cost & 3.0 & 5.0 & 4.0 & 4.0 \\
\hline Power density & 5.0 & 3.5 & 2.5 & 3.5 \\
\hline Maturity & 4.0 & 5.0 & 5.0 & 4.0 \\
\hline Efficiency & 5.0 & 3.5 & 2.5 & 3.5 \\
\hline Reliability & 4.0 & 5.0 & 3.0 & 5.0 \\
\hline
\end{tabular}

\begin{tabular}{|l|l|l|l|l|}
\hline Controllability & 4.0 & 5.0 & 5.0 & 3.0 \\
\hline Total & 25.0 & 27.0 & 22.0 & 23.0 \\
\hline
\end{tabular}

Low-cost hall sensors are used a lot for BLDC drives where the phase currents only have to be commutated on and off. Expensive resolvers or encoders need to be used for BLAC drives where the phase current waveforms require finely specific control. More recently, methods that do not require sensors are currently being tested and implemented for both of these drives. Regardless, it is a vital requirement that motors be provided with alternating current. Otherwise, they would not be able to rotate.

Despite the name that a Brushless DC motor (BLDC) suggests, it is considered an AC motor. Its function can be described by concentrated coil windings on the stator working together with surface mounted magnets on the rotor to create a closely uniform flux density in the airgap. Through this, a constant DC voltage allows the stator coils to be driven, switching from one stator coil to the next (commutation) - this is what gives this motor the name brushless DC. Commutation is electronically synchronized to the rotor angular position. An AC voltage waveform resembling a trapezoidal shape is resultant of this. The BLDC motor is absent of arcing issues that are seen with brushed DC motors since it does not use brushes or commutator. Essentially, the brushless DC electric motor can be considered and described as a brushless AC motor - containing an integrated power inverter and rectifier, sensor and inverter control electronics [8].

Considering the primary purpose of this research is to design a proper powertrain system for MHEV. PMSM, as the mainstream product on the HEV market, is selected as a propulsion motor for further study.

TABLE II. Symbols USED.

\begin{tabular}{|l|l|l|}
\hline Symbol & Definition & Unit \\
\hline$V_{a} V_{b} V_{c}$ & Terminal phase voltage & $\mathrm{V}$ \\
\hline$I_{a} I_{b} I_{c}$ & Motor input current & $\mathrm{A}$ \\
\hline$e_{a} e_{b} e_{c}$ & Motor back-EMF & $\mathrm{V}$ \\
\hline $\mathrm{R}$ & Armature resistance & $\Omega$ \\
\hline $\mathrm{L}$ & Armature self-inductance & $\mathrm{H}$ \\
\hline$K_{w}$ & Back EMF constant of one phase & $\mathrm{V} / \mathrm{rad} . \mathrm{sec}-1$ \\
\hline$\theta_{e}$ & Electrical rotor angle & $\mathrm{o}$ \\
\hline$\omega$ & Rotor speed & $\mathrm{rad} . \mathrm{sec}-1$ \\
\hline$\theta_{m}$ & Mechanical rotor angle & $\mathrm{rad}$ \\
\hline$T_{e}$ & Electromagnetic torque & $\mathrm{Nm}$ \\
\hline$T_{l}$ & The load torque & $\mathrm{Nm}$ \\
\hline$J$ & The inertia & $\mathrm{kgm} 2$ \\
\hline $\mathrm{B}$ & Friction constant & $\mathrm{Nms} . \mathrm{rad}-1$ \\
\hline
\end{tabular}

\section{B. $\quad P M S M / B L D C$ mathematical model}

The motor is expressed as follows and Table II contains all used symbols definition.

$$
\begin{aligned}
& V_{a}=R i_{a}+L \frac{d i_{a}}{d t}+e_{a} \\
& V_{b}=R i_{b}+L \frac{d i_{b}}{d t}+e_{b} \\
& V_{c}=R i_{c}+L \frac{d i_{c}}{d t}+e_{c}
\end{aligned}
$$


A function of rotor position and the back-EMF of each phase has $120^{\circ}$ phase angle difference to the equation of each phase should be as follows:

$$
\begin{gathered}
e_{a}=K_{w} f\left(\theta_{e}\right) \omega \\
e_{b}=K_{w} f\left(\theta_{e}-2 \pi / 3\right) \omega \\
e_{c}=K_{w} f\left(\theta_{e}+2 \pi / 3\right) \omega
\end{gathered}
$$

The electrical rotor angle is equal to the mechanical rotor angle multiplied by the number of pole pairs $p$ :

$$
\theta_{e}=\frac{p}{2} \theta_{m}
$$

The large airgap between stator and rotor, the saturation is neglected. Therefore, the flux linkages become a linear function of the phase currents. Total torque output can be represented as a summation of that of each phase. Next equation represents the total torque output:

$$
T_{e}=\left(e_{a} i_{a}+e_{b} i_{b}+e_{c} i_{c}\right) / \omega
$$

The equation of mechanical part represents as follows:

$$
T_{e}-T_{l}=J \frac{d \omega}{d t}+B \omega
$$

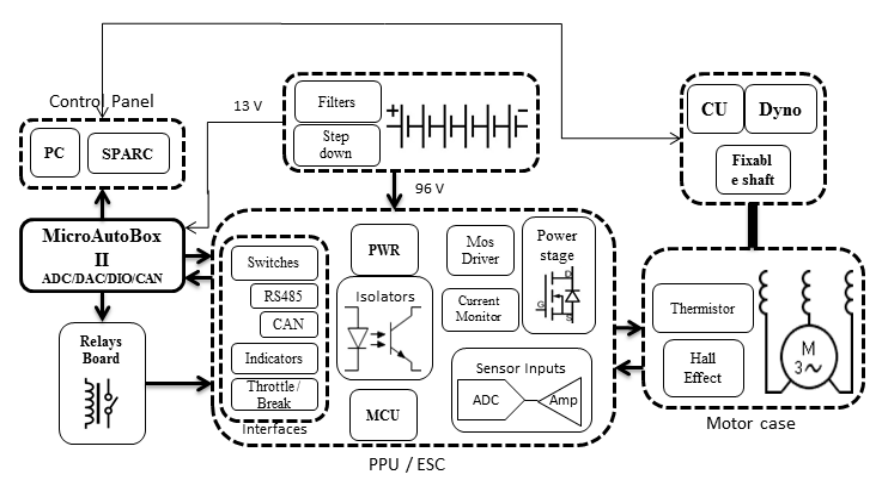

Fig. 1. The functional block diagram of EPS.

\section{EPS ORDERED}

In Fig. 1, a diagram of the EPS is shown. It includes six parts: the electric motor, KHB1260124 power converter, used to supply the Mars 0913 motor with electric power, and the Electronic Speed Control (ESC) to provide efficient, smooth and quiet controls [11]. The ESC manages the current supplied to each phase, polarity, the position of the rotor through BackEMF, monitors the speed, Hall-effect position sensors and then controls the operation of the electric motor to produce the required torque and speed, according to the command from the supervisory controller through the CAN network [12]. It is also used to read the physical motor parameters speed and temperature. dSPACE MicroAutoBox II is used to provide supervisory control to the motor controller by reading information through the CAN-bus into a feedback control loop, and issuing commands to the motor controller using analog and digital signals through the interface circuitry. The interface circuitry is a custom-designed relay board and wire connections. It is the interface that combines the output ports, e.g. sensor signals, CAN bus signals and motor driver command signals. Relays control system power; throttle and brake enable, and motor direction. Other functions are controlled by analogue control signals and CAN-based feedback. For the purpose of proof-of-concept, the motor is powered by a grid-connected $157 \mathrm{~kW}$ variable DC power supply, due to safety issues associated with battery storage and discharge in the laboratory environment.

\section{A. $\quad$ The motor ordered}

The Motenergy ME0913 electric motor was found to satisfy requirements. It is listed in Table III. The motor was selected as a suitable off-the-shelf motor for initial testing. The manufacturer quotes a thermal efficiency of $85 \%$ at its full continuous power, which translates to $10.2 \mathrm{~kW}$ mechanical output. Although its peak torque is somewhat lower than ideal, it is the closest off-the-shelf solution to meet the required hardware needs. The characteristics of the selected motor in combination with the matching inverter KHB1260124 are demonstrated in Fig. 2 [13].

The model was developed and programmed into the MicroAutoBox II boot. It is automatically converted to code, using the automatic code generation function of the real-time interface. The real-time simulation is running in dSPACE ControlDesk. This software allows logical configuration of simulation runs. Fig. 3 shows the cockpit layout of the realtime simulation. It detailed in next section.

\section{B. Rapid Prototype Verification}

The test facilities at UTS that were used in this study are shown in Fig. 2. They consist of an electric propulsion system, and a Horiba Schenck WT190 water-cooled eddy-current dynamometer. The motor is connected with dyno through a custom-machined companion flange and shaft adapter, as well as a GWB473-series Cardan shaft. An ABB DCS550 DC drive provides the DC power. The supply is capable of supplying up to $157.5 \mathrm{~kW}$ at $450 \mathrm{~V} \mathrm{DC}$. For testing constant-duty power levels, it was set to $96 \mathrm{~V}$, and up to $120 \mathrm{~A}$., The test was controlled through the Horiba Schenck SPARC controller and the dashboard in ControlDesk.

\section{Control panel}

Fig. 3 shows the layout of the control panel of the real-time test rig simulation for setting up important parameters such as IM speed, ESC parameters, and so on. The MicroAutoBox II controller receives commands from ControlDesk through a host interface cable. The commands control the parameters including Throttle, Brake, Reverse motor direction and KHB power switch. These commands were interpreted by the controller logic and applied to the KHB motor driver (responsible for managing the speed and position and working as data acquisition through CAN bus). The ControlDesk dashboard was configured to allow control of power, throttle, brake, and direction. Indicators were configured to display controller and motor temperatures, motor speed, direction, motor current, voltage, CAN-Bus activity, power status, and a speed histogram. The simulation results can also be logged using recorders. Recorded data can be exported to Matlab for further analysis. 


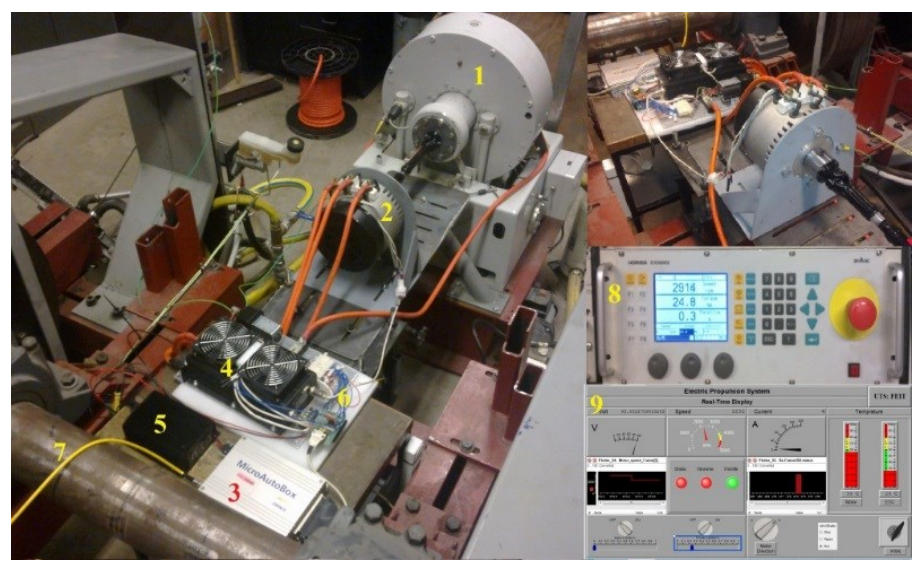

Fig. 2 EPS test facility at UTS [14]

1-Dynamometer WT190. 2- Mars 0913 PMSM/BLDC. 3-MicroAutoBoxII. 4KHB1260124. 5-Step-down 96 V/13.5 V. 6-Relays Board. 7-PC host interface. 8- SPARC control (Dyno stand controller). 9-Control Desk.

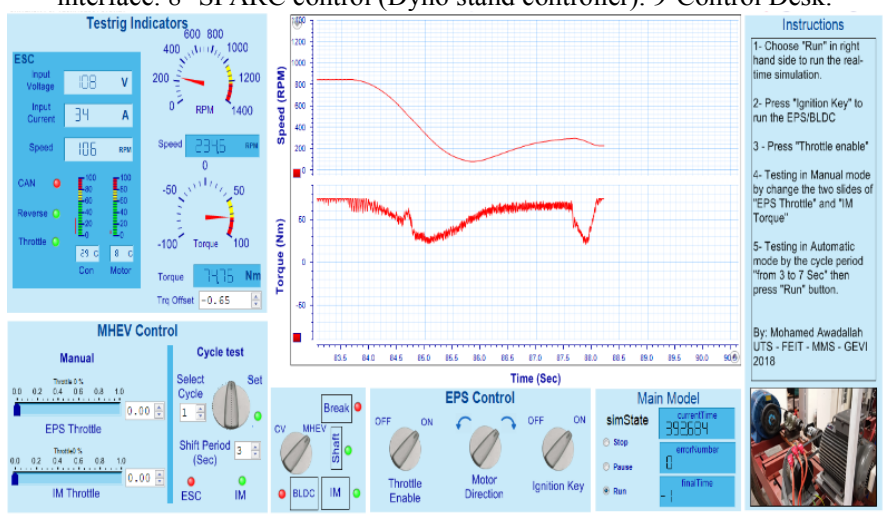

Fig. 3. Test rig cockpit in ControDesk.

Table III. Mars 0913(Etek Comparable) PMSM/BLDC motor.

\begin{tabular}{|l|l|}
\hline Parameter & SI Units \\
\hline Continuous Output Power & $12 \mathrm{KW}$ \\
\hline Peak Power at 96 volts & $30 \mathrm{KW}$ \\
\hline Voltages range & 0 to $96 \mathrm{VDC}$ \\
\hline AC Continuous current & $125 \mathrm{~A}$ \\
\hline DC Continuous current & $180 \mathrm{~A}$ \\
\hline AC Peak current & $420 \mathrm{~A}$ \\
\hline DC Peak current & $600 \mathrm{~A}$ \\
\hline Efficiency & $92 \%$ (at voltages between 24 to 96 VDC) \\
\hline Winding resistance & 0.013 Ohms (Phase to Phase) \\
\hline Maximum speed & $5000 \mathrm{RPM}$ \\
\hline Torque constant & $0.15 \mathrm{Nm} /$ Amp \\
\hline Peak Stall Torque & $90 \mathrm{Nm}$ \\
\hline Cooling & Fan Cooled motor \\
\hline Weight & $15.8 \mathrm{Kg}$ \\
\hline \multirow{2}{*}{ Inductance } & $0.10 \mathrm{~m} \mathrm{Henry} \mathrm{(Phase} \mathrm{to} \mathrm{Phase)}$ \\
\cline { 2 - 2 } & 28 turns per phase \\
\hline Armature Inertia & $45 \mathrm{Kg}$ Cm ${ }^{2}$ \\
\hline No of poles and magnets & 4 pole motor (8 magnets) \\
\hline Electric Connection & 3 -phase, Y-connected \\
\hline Axial rotor motor & Axial air gap \\
\hline \multirow{2}{*}{ Sensors } & $\begin{array}{l}3 \text { Hall sensors (at 120 degrees electrical } \\
\text { timing) }\end{array}$ \\
\hline Stators & Two stators with a rotor in the centre \\
\hline
\end{tabular}

A Data Acquisition Interface (DAI) module, integrated into the MicroAutoBox II was used for data collecting and recording. The DAI was programmed from within ControlDesk. Torque was measured using the SPARC dynamometer controller, and efficiency computation completed within MATLAB. The DAI module was programmed to measure and record the necessary parameters (current, speed and temperature) of the motor while it was running on the dynamometer. The complete experimental procedure required several iterations. To create the efficiency map, the motor was set to a fixed no-load speed (voltage) starting from the maximum speed down to $1000 \mathrm{rpm}$ in steps of $500 \mathrm{rpm}$. At each speed interval, the load torque was increased from zero in steps of $0.5 \mathrm{Nm}$ and maintained for 10 seconds. The maximum developed motor torque was determined when the brake torque applied by the dynamometer resulted in a non-stable operating point (that is, the motor speed could not be stabilized constant). At this point, brake torque was released, and the next no-load speed was set. The sampling frequency used for the preliminary data acquisition was $0.5 \mathrm{~Hz}$. Once the whole load range of the motor was measured, the parameters were analysed and validated in Matlab.

At low rpm and high torque, the system approached the control limit of the dynamometer and results were not necessarily accurate [15]. To complete testing as comprehensively as possible, when the control limit was reached, the dynamometer was controlled for a speed of zero, which is not practically possible using the equipment available and results in a system speed of around $15 \mathrm{rpm}$. This speed allows us to approximate speed/torque characteristics of the motor at close to zero rpm. However, this test could not be sustained for long periods due to the possibility of mechanical failure of the motor. The current supplied to the motor did not exceed $105 \mathrm{~A}$ in these results, despite the motor being rated to 180 A peak/125 A continuous. This was because of the elevated case temperatures evident, which indicated that mechanical failure was likely at higher loads. Because of the air-cooled design of the motor, this was a significant limitation.

Our results show that maximum power of $9.8 \mathrm{~kW}$ was obtained in the region of 2600-3000 rpm. Fig. 4 shows the maximum torque and power curve of the motor. Motor efficiency was calculated numerically as the output mechanical power of the motor divided by the AC power supplied to the motor by the controller. AC power was determined by multiplying the measured DC power supplied to the inverter by a fixed efficiency value of $98 \%$ [16].
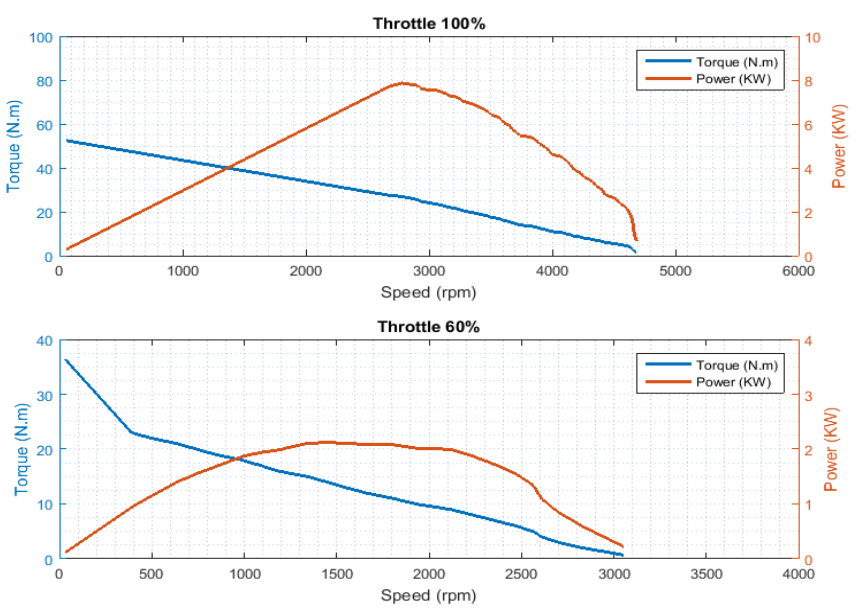

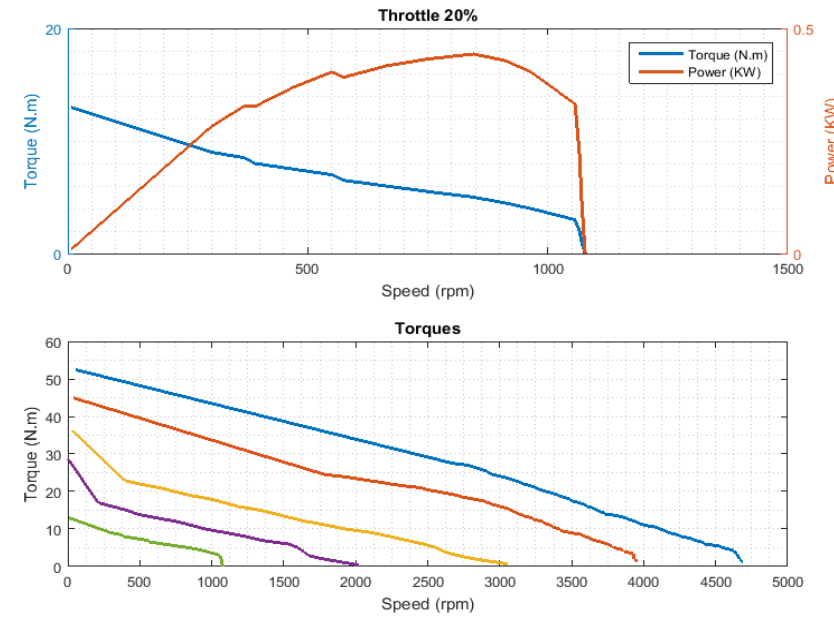

Fig. 4 Torque and Power vs Speed of the motor at different throttles.

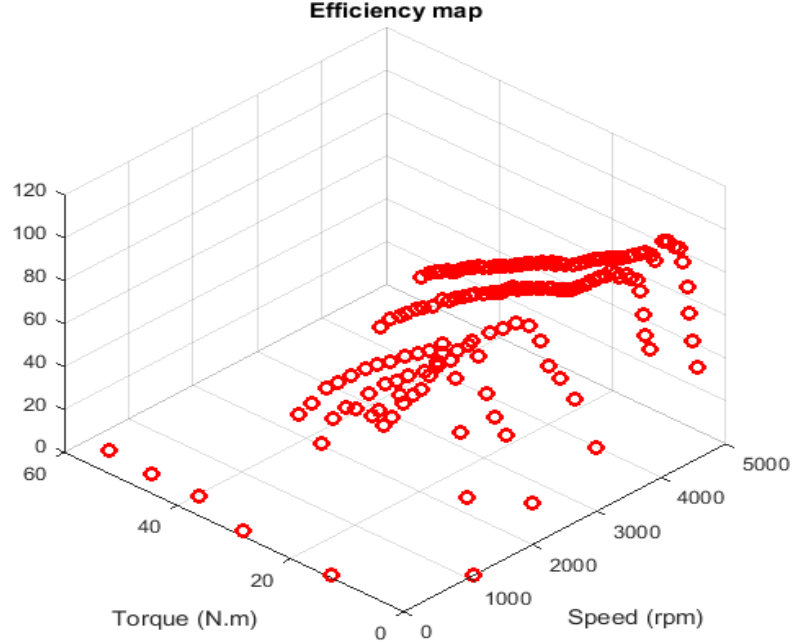

Fig. 5 Efficiency map of the electric propulsion system.

Fig. 5 shows the three-dimensional efficiency map for the motor. The low-efficiency regions are a low-speed, high load conditions. The average efficiency is about $85 \%$ for the system, which includes power loss in the motor, controller, and mechanical losses. The manufacturer-rated power of the motor could not be reached during testing. Specifically, this was 12 $\mathrm{kW}$ continuous and $30 \mathrm{~kW}$ peak. However, the rated peak efficiency of $92 \%$ was demonstrated, and a peak efficiency of $95.4 \%$ was observed during testing. Rated peak torque of 90 N.m (stall) could not be observed, due to limitations of the apparatus. Maximum torque of 52.5 N.m was measured at 50 $\mathrm{rpm}$. It is doubtful that the rated peak torque can be practically achieved due to mechanical limitations in the construction of the motor.

\section{Efficiency analysis}

The mechanical power is the product of torque and speed of the motor equation (10) was used to calculate the efficiency of electric motors directly (IEEE 112-B, CSA-390).

$$
\text { Motor Eff }=\frac{\text { Output mechanical power }}{\text { AC Input electrical power }} \times 100 \%
$$

The average efficiency is $82 \%$. Although our testing could not validate manufacturer claims, it shows that this motor can nevertheless meet our design target. The losses were not calculated individually, but can be classified as electrical losses, magnetic losses (core loss, iron power and copper loss), mechanical losses, and stray load losses, previously investigated in $[17,18]$. The experimental verification procedure consisted of various steady state and transient tests ranging from maximum torque runs to the continuous power of the motor. Table IV shows the results obtained for some of the tested parameters.

TABLE IV. EPS VALIDATION RESUlTS.

\begin{tabular}{|l|l|}
\hline Peak Power & $9.8 \mathrm{~kW}$ \\
\hline Peak Torque & $54 \mathrm{Nm}$ \\
\hline Continuous Power & $8 \mathrm{~kW} @ 2800 \mathrm{rpm}$ \\
\hline Continuous Torque & $28 \mathrm{Nm} @ 2800 \mathrm{rpm}$ \\
\hline Continuous Power (2 minutes) & $4 \mathrm{~kW} @ 4000 \mathrm{rpm}$ \\
\hline Continuous Torque (2 minutes) & $10 \mathrm{Nm} @, 4000 \mathrm{rpm}$ \\
\hline Peak Efficiency & $95.4 \%$ \\
\hline
\end{tabular}

\section{HIL TEST RIG EXPERIMENT AND VERIFICATION}

Hardware-in-the-loop (HIL) simulation has been established as a development step in the automotive industry. Unlike test drives in a real vehicle, these tests are performed in the lab, so that errors that occur can be reproduced at any time. HIL techniques that allow HEV architecture development speedy without waiting for the new battery pack and ICE to become available. The HIL test system replaces the real environment of the EPS (ECU, Motor, etc.) and the tests can be executed in any test scenario. HIL testing is a standard step in a rapid control prototyping [19].

\section{A. Integration and Experimental Setup}

Referring to Fig. 6, the EPS is central to the HEV. It consists of an electric motor, power converter, and electronic controllers. The IM is the tool that is used to emulate the real output of the manual transmission. The IM is controlled by an $\mathrm{ABB}$ motor controller. Both the $\mathrm{ABB}$ and the electronic controller in the EPS are commanded by a supervisory controller. The supervisory controller is based on dSPACE ControlDesk and is implemented on a dSPACE MicroAutoBox II control unit. The supervisory controller is programmed with a vehicle model, which is used to generate torque commands for both the IM and the EPS. A shaft connects the IM and the eddy brake, emulating the propshaft in a real vehicle. The eddy brake acts as a brake based on a road load model, to simulate rolling, aerodynamic, and inertial resistance loads. The supervisory controller runs a model based on real data acquired from a vehicle, which gives torque profile, vehicle speed, and gear changes. Fig. 7 demonstrates the structure and components of the powertrain test rig. An offline tested MHEV powertrain control model can be loaded into MicroAutoBox to acquire data, watch and change variables, through setting up an interactive window in PC as monitoring software interface. dSPACE ControlDesk environment was used to develop a realtime interface (RTI) in the host PC, permitting user control of the simulator. Major components used in this experimental setup are listed in Table V. 

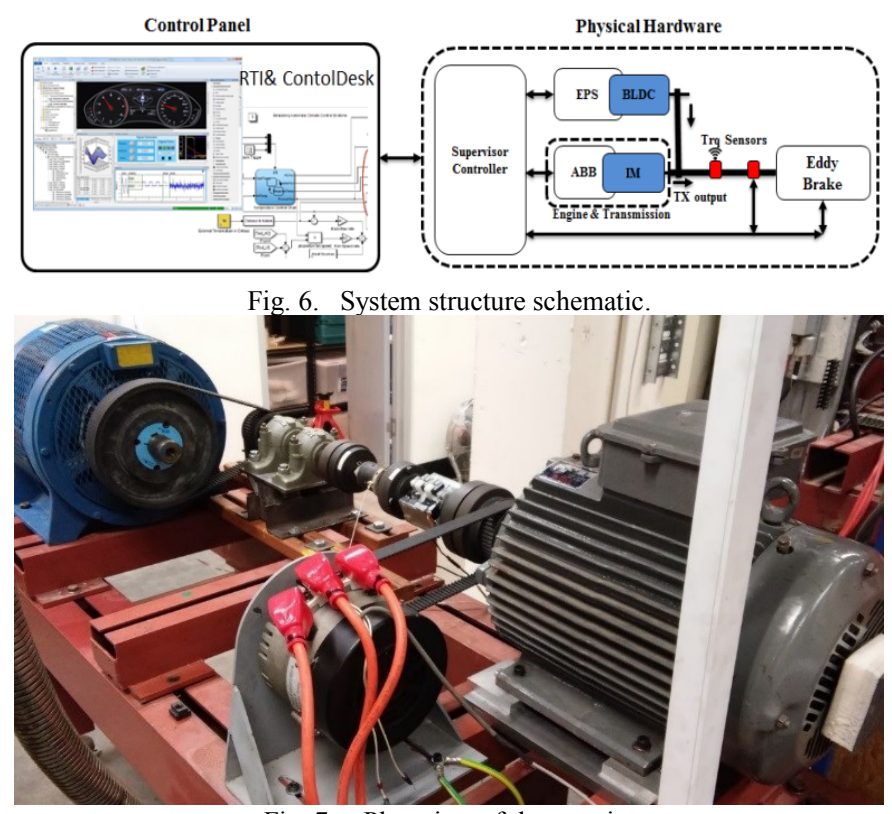

Fig. 7. Plan view of the test rig.

TABLE V. LIST OF MAJOR COMPONENTS OF THE EXPERIMENTAL SETUP.

\begin{tabular}{|l|l|}
\hline Component & Description/Brand Model \\
\hline Dynamometer & DSI-AS706 \\
\hline Incremental Encoder & K̈ubler-05.2420.1222.1024 \\
\hline BLDC Controller & Kelly-KHB12601, 24-120 V, 600 A \\
\hline BLDC Motor & Mars 0913 BLDC \\
\hline Supervisor Controller & MicroAutoBoxII \\
\hline IM motor & McCOLL 180M - 22 KW \\
\hline IM Controller & ACS355-03E-44A0-4 \\
\hline
\end{tabular}

\section{B. $\quad$ Case study Architecture}

The hybrid configuration specified in this research is based on a low-powered, output shaft-mounted electric motor, connected to the output shaft of an MT and powered with a controlled power source. The motor is mounted after the gearbox, over-rev protection is not required. Instead, the engine rev limiter and appropriate gearing ratios are used to limit motor speed naturally. Such a configuration is typically defined as a post-transmission parallel-type hybrid vehicle powertrain (P3). The architecture of the model can be seen in Fig. 8. More detailed specific features are presented before in $[20,21]$ outlines the vehicle parameters which were used in the model.

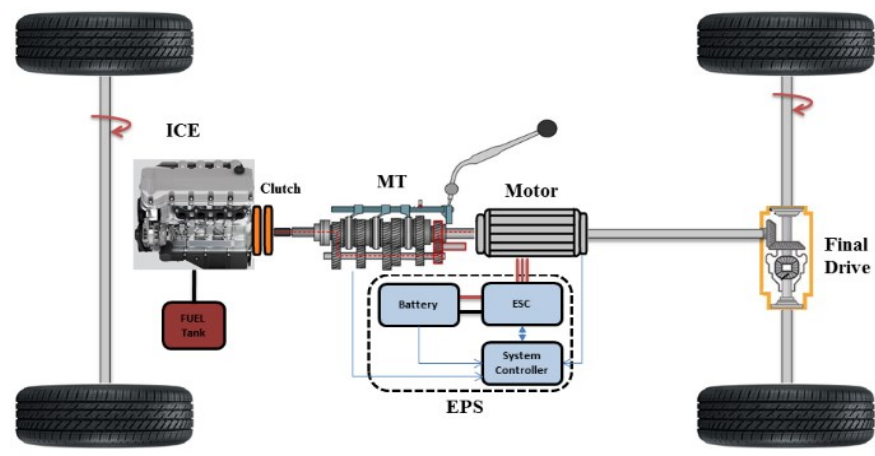

Fig. 8. Powertrain Architecture.
This research aims to eliminate the transient transmission torque response in a manual transmission with a mild hybrid technique. It presents a detailed investigation into the torque hole of a typical manual transmission. Finally, to validate the HIL experimental system is utilised to evaluate shift control performance with and without torque compensation. The HIL test rig is used to simulate the output torque of a manual transmission equipped vehicle, with particular reference replicating the torque hole. Furthermore, some of the major technical outcomes, particularly shift control and behaviour, are verified using HIL simulation of an exemplary powertrain system $[22,23]$.

\section{Test scenario}

In the case of our mild HEV hardware-in-the-loop setup, the hardware and software are fully integrated. The software controls emulation of the output of manual transmission and EPS concurrently in real time [24]. The BLDC motor command comes from the power management module (Kelly controller) via the virtual driver handled by the MicroAutoBox II, rather than directly. The test scenario is setup as follows. A constant torque and speed are achieved (Cruising) where the IM motor is initially rotating at 800 RPM with constant torque. A gear change is then commanded, which is simulated by a drop to zero torque output by the IM motor. The torque sensor recognises the drop-in torque and commands the BLDC motor such that the torque hole is filled. Once torque resumes, the BLDC motor is de-energized. The resulting data can then be acquired and analysed for calibration of the system and enhancement of the emulation fidelity. From a control perspective, the control signals are passed to MicroAutoBox II and processed into a command that is sent to the $\mathrm{ABB}$ controller of the Induction Motor. The updated vehicle velocity is subsequently translated to the IM motor, based on change states in the transmission by a virtual driver, and this request is sent to the model through MicroAutoBox II. With a change in target torque simulating gear change, the virtual driver integrated into the simulation assesses the difference in actual motor speed and reacts to increase the speed position as required. MicroAutoBox II receives the speed position signal, processing the signal to the IM motor through the ABB Control interface. Concurrently, the updated vehicle velocity is also provided to the EPS Model, which again compares this value to the driving schedule and determines the torque hole for the following step. When the desired vehicle velocity profile starts to fall, the EPS model sends an appropriate command to the BLDC motor to eliminate the torque hole, which is measured by using a shaft-mounted transducer. The values gained from the measured torque are input to the simulation module, which can assess the impact of the supplied torque on BLDC motor velocity. The resulting motor velocity is consequently converted to motor speed. The simulation is run simultaneously with the hardware and communicated with MicroAutoBox II throughout the testing duration. The updated speed and torque are provided to the model, which again compares this value to the old data without EPS to show the torque elimination [25]. 


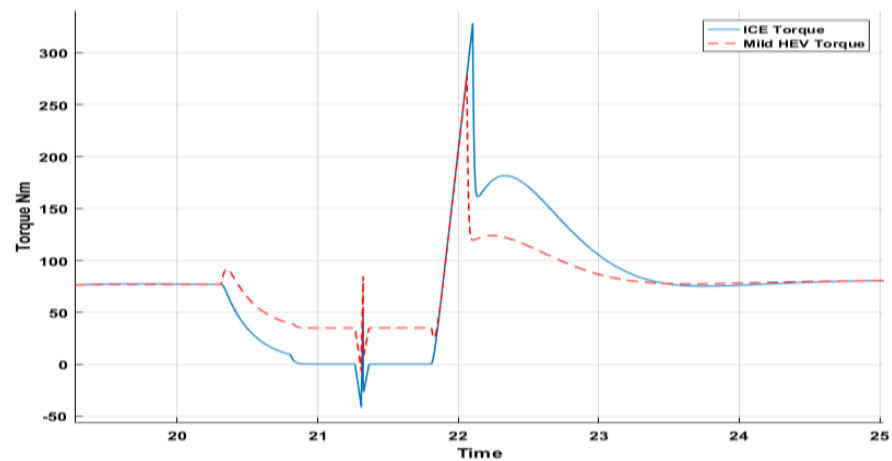

Fig. 9. shows torque output of a gear shift from 2 nd to 3 rd gear.

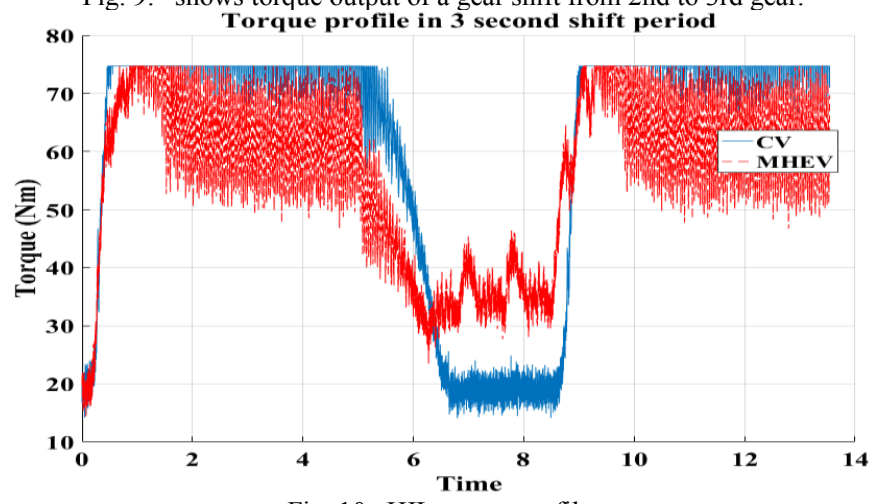

Fig. 10. HIL torque profile.

Upshifting from $2^{\text {nd }}$ to $3^{\text {rd }}$ gear was selected for its simplicity and utilises that test scenario was selected as an initial benchmark for its simplicity and its ability to highlight gear shift characteristics consistently. Up-shifting control can be finished in 4 Seconds. During the inertial phase, motor torque drop down close to zero and then recover. As predicted in simulations, a large hole in the output torque and a corresponding decrease are evident during the gear shift process, shown in Fig. 9. The results demonstrate the shaft speed variation resulting from the selection of varying gear ratios, as well as the transient system response. When operating in torque-fill mode, the resultant shows marked reduction is oscillation amplitude and a reduced torque hole magnitude. The torque oscillation is of particular interest, showing a reduction of $40 \mathrm{Nm}$. Based on transmission output shaft sensors.

The difference between experimental and simulation results is largely due to the variation of PID-control strategies. The differences result in variations in the demand requirements between the two scenarios. The experiment results of torque hole, it is shown in Fig. 10. The results demonstrate the capability of the HIL model to simulate the behaviour of the real system.

\section{CONCLUSION}

Experimental validation of the rated characteristics of a PMSM electric machine was conducted. The experimental validation used HIL techniques implemented on a dSpace MicroAutoBox II supervisory controller, which controlled a motor controller and, in turn, the PM motor. The HIL system was designed and implemented in the MATLAB/Simulink environment and transferred directly into dSpace ControlDesk. The rated torque and power characteristics could not be achieved in the current testing, although it was found that the motor could still achieve design parameters set for use in a Mild Hybrid Electric Vehicle. The motor exceeded the manufacturer-rated peak efficiency of $92 \%$, achieving a peak efficiency of $95.4 \%$.

One of the most important parts of the works is the HIL system development. This was developed using the dSPACE MicroAutoBox II. The control hardware, software and electrical schematics were developed.

The HIL technique with Motor-in-the-loop allows the same control setup to be used after validation for control of the motor when it is deployed in the prototype vehicle. Developing an HIL control system at this stage dramatically reduces the prototyping cycle time as no further design work is required for building a controlled environment within the prototype vehicle.

\section{REFERENCES}

[1] T. Hutchinson, S. Burgess, and G. Herrmann, "Current hybrid-electric powertrain architectures: Applying empirical design data to life cycle assessment and whole-life cost analysis," Applied Energy, vol. 119, pp. 314-329, 2014.

[2] C. Chan and Y. Wong, "Electric vehicles charge forward," Power and Energy Magazine, IEEE, vol. 2, no. 6, pp. 24-33, 2004.

[3] Z. Rahman, M. Ehsani, and K. Butler, "An investigation of electric motor drive characteristics for EV and HEV propulsion systems," SAE transactions, vol. 109, no. 6, pp. 2396-2403, 2000.

[4] M. Zeraoulia, M. E. H. Benbouzid, and D. Diallo, "Electric motor drive selection issues for HEV propulsion systems: A comparative study," Vehicular Technology, IEEE Transactions on, vol. 55, no. 6, pp. 1756-1764, 2006.

[5] M. Ehsani, Y. Gao, and A. Emadi, "Electric Propulsion Systems," in Modern electric, hybrid electric, and fuel cell vehicles: fundamentals, theory, and designSecond ed.: CRC press, 2009.

[6] S. Sharma and V. Kumar, "Optimized Motor Selection for Various Hybrid and Electric Vehicles," SAE Technical Paper2013.

[7] L. Chang, "Comparison of AC drives for electric vehicles-a report on experts' opinion survey," Aerospace and Electronic Systems Magazine, IEEE, vol. 9, no. 8, pp. 7-11, 1994.

[8] M. Awadallah, P. Tawadros, P. Walker, and N. Zhang, "Selection and Characterisation of PMSM motor for mild HEV Applications," in 29th Electric Vehicle Symposium 2016 (EVS29), Montréal, Québec, Canada, 2016, pp. 1276-1286: Electric Drive Transportation Association ( EDTA ).

[9] M. Awadallah, P. Tawadros, P. Walker, and N. Zhang, "A Low-Cost and Novel Approach in Gearshift Control for a Mild-Hybrid Powertrain," in IEEE Transportation Electrification Conference and Expo 
(ITEC), 2017 IEEE, Chicago, Illinois, USA, 2017, pp. 754-760: IEEE.

[10] C. Chan, "The state of the art of electric and hybrid vehicles," Proceedings of the IEEE, vol. 90, no. 2, pp. 247-275, 2002.

[11] K. Controls. (2008, 12/1/2015). KHB12601,24120V,600A,Opto BLDC Controller/With Regen. Available: http://kellycontroller.com/khb1260124120v600aopto-bldc-controllerwith-regen-p-830.html

[12] J. C. Gamazo-Real, E. Vázquez-Sánchez, and J. Gómez-Gil, "Position and speed control of brushless DC motors using sensorless techniques and application trends," Sensors, vol. 10, no. 7, pp. 69016947, 2010.

[13] M. Awadallah, P. Tawadros, and N. Zhang, "Rapid Prototyping and Validation of Mars 0913 Brushless Motor to Develop Mild HEV," in The 7th TM Symposium China (TMC2015), Shanghai, China, 2015, vol. 1, pp. 92-98: SAE-China, 2015.

[14] M. Awadallah, P. Tawadros, P. Walker, and N. Zhang, "A System Analysis and Modeling of a HEV based on Ultracapacitor Battery," in IEEE Transportation Electrification Conference and Expo (ITEC), 2017 IEEE, Chicago, Illinois, USA, 2017, pp. 792-798: IEEE.

[15] J. Song and Q. Chen, "A Study of Dynamic Electric Dynamometer Based on Separate-excited DC Generator," Journal of Asian Electric Vehicles, vol. 3, no. 1, pp. 673-676, 2005.

[16] D. Hari, C. Brace, C. Vagg, S. Akehurst, L. Ash, and R. Strong, "Development and Testing of a Low Cost High Performance Hybrid Vehicle Electric Motor," SAE Technical Paper2013.

[17] C. Cavallaro, A. O. D. Tommaso, R. Miceli, A. Raciti, G. R. Galluzzo, and M. Trapanese, "Efficiency enhancement of permanent-magnet synchronous motor drives by online loss minimization approaches," Industrial Electronics, IEEE Transactions on, vol. 52, no. 4, pp. 1153-1160, 2005.

[18] A. T. De Almeida, F. J. Ferreira, J. F. Busch, and P. Angers, "Comparative analysis of IEEE 112-B and IEC 34-2 efficiency testing standards using stray load losses in low-voltage three-phase, cage induction motors," Industry Applications, IEEE Transactions on, vol. 38, no. 2, pp. 608-614, 2002.

[19] A. Wagener, T. Schulte, P. Waeltermann, and H. Schuette, "Hardware-in-the-Loop Test Systems for Electric Motors in Advanced Powertrain Applications," in SAE World Congress \& Exhibition, 2007: SAE International.

[20] M. Awadallah, P. Tawadros, P. Walker, and N. Zhang, "Dynamic modelling and simulation of a manual transmission based mild hybrid vehicle," (in English), Mechanism and Machine Theory, vol. 112, pp. 218-239, June 20172017.

[21] M. Awadallah, P. Tawadros, P. Walker, and N. Zhang, "Comparative fuel economy, cost and emissions analysis of a novel mild hybrid and conventional vehicles," Proceedings of the Institution of Mechanical Engineers, Part D: Journal of Automobile Engineering, p. 17, November 8, 2017 2017.

[22] M. Awadallah, P. Tawadros, P. Walker, and N. Zhang, "Eliminating the torque hole: Using a mild hybrid EV architecture to deliver better driveability," in 2016 IEEE Transportation Electrification Conference and Expo, Asia-Pacific (ITEC AsiaPacific), Busan, South Korea, 2016, pp. 173-179: IEEE.

[23] M. Awadallah, P. Tawadros, P. Walker, and N. Zhang, "Comparative System Dynamic Modeling of a Conventional and Hybrid Electric Powertrain," in Power Engineering - International conference on Power Transmissions (ICPT 2016), Y. S. Datong Qin, Ed. Chongqing, China: CRC Press, 2016, pp. 231238.

[24] J. Allen, "Simulation and Test Systems for Validation of Electric Drive and Battery Management Systems," in Aerospace Electronics and Avionics Systems, 2012: SAE International.

[25] M. Awadallah, P. Tawadros, P. Walker, and N. Zhang, "A Comparative Fuel Analysis of a novel HEV with conventional vehicle," in Vehicular Technology Conference (VTC Spring), 2017 IEEE 85th, Sydney, Australia, 2017, pp. 1-6: IEEE. 